\title{
Influence of Photoinitiator and Light- Curing Source on Bond Strength of Experimental Resin Cements to Dentin
}

\author{
Dario Raimundo Segreto ${ }^{1}$, Fabiana Scarparo Naufel ${ }^{2}$, William Cunha Brandt ${ }^{3}$, \\ Ricardo Danil Guiraldo ${ }^{4}$, Lourenço Correr-Sobrinhoํ․, Mário Alexandre \\ Coelho Sinhoreti ${ }^{1}$
}

\begin{abstract}
This study evaluated the bond strength (BS) of experimental resin cements formulated with different photoinitiators when activated by two kinds of light-curing units (LCUs) through a ceramic material. Seven resin blends with different camphorquinone (CQ) and/ or phenylpropanedione (PPD) concentrations (weight) were prepared: $\mathrm{C} 5: 0.5 \% \mathrm{CQ} ; \mathrm{C}$ : 0.8\% CQ; P5: 0.5\% PPD; P8: 0.8\% PPD; C1P4: 0.1\% CQ and 0.4\% PPD; C4P1: 0.4\% CO and $0.1 \%$ PPD; C4P4: $0.4 \%$ CO and 0.4\% PPD. Two LCUs were used: one quartz-tungstenhalogen (OTH - $850 \mathrm{~mW} / \mathrm{cm}^{2}$ ) and one light-emitting diode (LED - $1300 \mathrm{~mW} / \mathrm{cm}^{2}$ ). The microtensile bond strength of each blend was assessed. Data were submitted to two-way ANOVA and Tukey's test $(\alpha=0.05)$. The BS values did not exhibit significant differences for LCUs, regardless of the photoinitiator type. Three cements showed significant differences: P5 and C5 had higher BS with QTH, and C4P1 with LED. For QTH, P5 showed the highest and $\mathrm{C} 1 \mathrm{P} 4$ the lowest BS. For the LED, C4P1 showed the highest BS of all the cements. The results indicated that PPD was a viable alternative in the formulation of photocured resin cements, reducing or eliminating $\mathrm{CO}$ that is yellowish without impairing the bond strength. Furthermore, both LED and QTH were effective in curing resin cements that contain PPD or CQ.
\end{abstract}

\author{
'Department of Restorative \\ Dentistry, Dental Materials \\ Division, Piracicaba Dental School, \\ UNICAMP - Universidade Estadual \\ de Campinas, Piracicaba, SP, Brazil \\ ${ }^{2}$ Department of Restorative Dentistry, \\ Dental Materials Division, UNIOESTE \\ Universidade Estadual do Oeste \\ do Paraná, Cascavel, PR, Brazil \\ ${ }^{3}$ Dental School, UNISA - Universidade \\ Santo Amaro, São Paulo, SP, Brazil \\ ${ }^{4}$ Dental School, UNOPAR - \\ Universidade Norte do Paraná, \\ Londrina, PR, Brazil.
}

Correspondence: Mário Alexandre Coelho Sinhoreti, Av. Limeira, 901, 13414-903 Piracicaba, SP, Brasil. Tel: +55-19-2106-5345. e-mail: sinhoreti@fop.unicamp.br

\section{Introduction}

The use of indirect ceramic restorations is increasing due to their superior aesthetics, biocompatibility and long-term stability. "Etchable" ceramic restorations should be adhesively luted, as doing so improves the retention, marginal sealing and fracture resistance (1). The success of resin-bonded, all-ceramic restorations is highly dependent on obtaining a reliable bond and good polymerization (2). Handling chemically cured cement unavoidably creates occasional air bubbles in the resin mass, which can weaken some properties and compromise the bond strength. Therefore, two sorts of resin cements - lightcured and dual-cured - have been used for luting indirect ceramic restorations. Dual-cured cements have shown to be dependent on the light exposure to ensure their best properties, similar to those that are light-cured (3). The light-cured resin cements can be selected for fixing ceramic veneers on anterior teeth, because they allow more light to pass through, which helps to assure good bond strength. Akgungor et al. (4) concluded that up to $2 \mathrm{~mm}$ thick, light curing has no deleterious effect on BS.

Camphorquinone ( $\mathrm{CO}$ ) is the most widely used photosensitizer for visible light-cured resins. However, it has some disadvantages, such as low polymerization efficiency and toxicity (5). Further, CQ is a solid yellow compound and even small amounts of it in resin formulations may lead to undesirable yellowing that affects the final aesthetic appearance of the cured material (6). Another major problem is that the $\alpha$-diketone group derived from $\mathrm{CO}$, has peak absorption in the visible range $(468 \mathrm{~nm})$ (12), resulting in fast photopolymerization under ambient light (fluorescent lamps and dental lamps) and a short operation time (1). It is the reason why researchers have tested different photoinitiators in the organic matrix to substitute or act synergistically with CO (7-10).

Other initiators, such as diphenyl-phosphine oxide (TPO), can be especially useful in extra-white shades of resin-based composites (RBCs). Such initiators are often required in bleached teeth because they can eliminate the unwanted yellow effect of CO (11). Another interesting initiator is phenylpropanedione (PPD), which may improve the polymerization kinetics (7).

The curing technology is based on the use of photoreactive systems that absorb irradiation from the LCUs at a specific wavelength, allowing a higher degree of conversion (DC) that determines the final properties of RBCs. The success of RBC polymerization depends on matching the spectral emission of the LCU with the requirements of the photoinitiator system to convert the monomers into a polymer network (12). In other words, the photoinitiator activation occurs at specific wavelengths, and optimum efficiency is obtained if the peak absorptivity 
of the photoinitiator corresponds to the spectral emission of the LCU. Therefore, it is important to consider that the PPD absorption spectrum extends from below $350 \mathrm{~nm}$ to approximately $490 \mathrm{~nm}$, extending into the violet range (which peaks at $390 \mathrm{~nm}$ ).

Due to the lack of outcomes regarding the effect of PPD on adhesion to ceramic and dentin, the bond strength must be evaluated. Therefore, the specific aim of this study was to evaluate the microtensile bond strength ( $\mu \mathrm{TBS}$ ) of seven experimental cements containing different photoinitiators at different concentrations, photoactivated by LED or QTH through ceramic material.

The tested hypotheses were: the bond strength of each experimental cement varies according to the type and concentration of the photoinitiator when photoactivated by LED or QTH; and the bond strength of each experimental cement differs according to LCU.

\section{Material and Methods}

\section{Cement Preparation}

Seven experimental cement formulations were tested in this study. The resin matrix for all the formulations consisted of a combination of bisphenol glycidyl methacrylate, ड 50.0\% wt (BisGMA; Sigma-Aldrich Inc., St. Louis, MO, USA); urethane dimethacrylate, 30.0\% wt (UDMA; SigmaAldrich); and bisphenol ethoxylate dimethacrylate, 20.0\% wt (TEGDMA; Sigma-Aldrich). The composites were loaded with 65\% wt silanated filler (25\% wt silica with 0.04 $\mu \mathrm{m}$ and $75 \%$ wt Ba-Al-silicate glass with $0.5 \mu \mathrm{m}-\mathrm{FGM}$, Joinville, SC, Brazil).

The only difference among the cements was the photoinitiator system (CO or PPD; Sigma-Aldrich); 1.0\% dimethylaminoethyl methacrylate (DMAEMA; SigmaAldrich) was always used as the co-initiator and $0.1 \%$ hydroquinone as the inhibitor. The tested photoinitiator systems are in Table 1.

The LCUs used in the study were a OTH (XL2500; 3M/ ESPE, St. Paul, MN, USA) and a LED (UltraLume LED5; Ultradent Products Inc., South Jordan, UT, USA) with a standardized diameter of $7 \mathrm{~mm}$ for the LCU tips using a centered black cover. All LCUs were analyzed with the standardized tip to be completely sure that the black cover would not affect the quality of light emission, especially of the UltraLume LED5.

The output power ( $\mathrm{mW}$ ) of each LCU was measured with a calibrated power meter (Ophir Optronics, Jerusalem, Israel). The light irradiance $\left(\mathrm{mW} / \mathrm{cm}^{2}\right)$ was determined by dividing the output power by the tip area. Spectral distributions were obtained by a calibrated spectrometer (USB2000; Ocean Optics, Dunedin, FL, USA). The irradiance and the spectral distribution data were integrated using Origin 6.0 software (OriginLab Northampton, MA, USA).

\section{Photoinitiators}

The absorption spectra of the photoinitiators (CO and PPD; Sigma-Aldrich) were determined by a UV-Vis spectrophotometer (Varian Cary 5G, Sidney, NSW, Australia). Only the visible and near-UV range was of interest (350-550 $\mathrm{nm})$, as this is the range that reflects the emission of LCUs. The absorption spectra were recorded separately for each photoinitiator (CO and PPD).

\section{Sample Preparation for the Microtensile Bond Strength Test}

A dentin smear layer was created by wet grinding the vestibular surfaces of 70 bovine incisors with \#600-grit silicon carbide paper (Extec), which were then randomly assigned to one of the 14 experimental groups $(n=5)$, one for each possible pairing of the seven experimental cements with both LCUs. Feldspathic ceramic discs with A3 shade (7.0 mm $\times 1.4 \mathrm{~mm}$ thick: IPS E.max Ceram; Ivoclar/Vivadent) were pre-treated with 10\% hydrofluoric acid (IPS Ceramic Etching Gel, Ivoclar-Vivadent, Schaan, Liechtenstein) for 20 s. Next, a silane primer (Rely X Ceramic Primer, 3M/ESPE) was applied and left untouched for $60 \mathrm{~s}$, followed by the application of an unfilled bonding agent (Adper Single Bond $2 ; 3 \mathrm{M} / \mathrm{ESPE}$ ), which was not light cured.

The ceramic blocks were luted onto the dentin surfaces using the experimental resin cements under a constant force of $1 \mathrm{~kg}$ for $1 \mathrm{~min}$ and then light-cured for $100 \mathrm{~s}$. Afterwards, the teeth were stored for $24 \mathrm{~h}$ in water at $37{ }^{\circ} \mathrm{C}$ in an incubator before being further processed and subjected to microtensile bond strength ( $\mu$ TBS) test.

Each specimen was sectioned in $\mathrm{x}$ and $\mathrm{y}$ direction by a high-precision Isomet 1000 diamond saw (Buehler, Lake Bluff, IL, USA) in order to obtain $\mu$ TBS specimens or beams with a cross-sectional area of approximately $1 \mathrm{~mm}^{2}$. Each bonded beam was fixed to the grips of a micro-tensile device (Odeme Dental Research, Luzerna, SC, Brazil) with

Table 1. Experimental groups and photoinitiator rates

\begin{tabular}{lcc}
\hline \multirow{2}{*}{ Cement } & \multicolumn{2}{c}{ Light-curing units } \\
\cline { 2 - 3 } C5 & CQ (\% wt) & PPD (\% wt) \\
C8 & 0.5 & -- \\
P5 & 0.8 & -- \\
P8 & -- & 0.5 \\
C1P4 & -- & 0.8 \\
C4P1 & 0.1 & 0.4 \\
C4P4 & 0.4 & 0.1 \\
\hline
\end{tabular}


cyanoacrylate adhesive (Zapit, DVA, Corona, CA, USA) and tested for $\mu$ TBS in a testing machine (model 4411, Instron Co., Canton, MA, USA) at $0.5 \mathrm{~mm} / \mathrm{min}$ until failure. After testing, specimens were removed from the fixtures with a scalpel blade and the cross-sectional area at the site of fracture was measured to the nearest $0.01 \mathrm{~mm}$ with a digital caliper (Starret 727-6/150, Starret, SP, Brazil).

\section{Failure Mode}

The specimens' mode of failure was determined by using scanning electron microscopy (LEO 435 VP; LEO Electron Microscopy Ltd., Cambridge, UK) at 100x magnification. The fractured surfaces were classified according to the prevailing remaining structure as Type I, adhesive; Type II, cohesive within cement; Type III, cohesive within dentin; or Type IV, mixed, involving at least two structures (ceramic, cement, bonding agent, hybrid layer or dentin).

\section{Statistical Analysis}

The statistical analysis employed two-way ANOVA. Comparisons were made using Tukey's post-hoc test $(p \leq 0.05)$.

\section{Results}

Table 2 exhibits the mean $\mu$ TBS (standard deviation; SD) of the seven experimental cements polymerized by the two LCUs. Two-way ANOVA showed significant differences in the interactions of the studied two independent variables (cement and LCU; $p=0.0001$ ).

Three cements (C5, P5 and C4P1) showed significant differences in BS when activated by each light source. For P5 and C5, BS was higher with $\mathrm{QTH}$; for $\mathrm{C} 4 \mathrm{P} 1$, BS was higher with LED. Independent of the LCU factor, for QTH P5 showed the highest BS with statistically significant difference from C1P4. For LED C4P1 showed the highest

Table 2. Mean (SD) $\mu$ TBS (MPa) of the experimental cements, lightcured with QTH and LED

\begin{tabular}{lcc}
\hline Cement & QTH & LED \\
\hline C5 & $16.8(1.6) \mathrm{A}, \mathrm{ab}$ & $12.8(1.7) \mathrm{B}, \mathrm{b}$ \\
C8 & $13.9(2.3) \mathrm{A}, \mathrm{b}$ & $14.8(2.8) \mathrm{A}, \mathrm{b}$ \\
P5 & $19.6(3.5) \mathrm{A}, \mathrm{a}$ & $13.4(3.0) \mathrm{B}, \mathrm{b}$ \\
P8 & $15.4(2.3) \mathrm{A}, \mathrm{ab}$ & $13.9(1.6) \mathrm{A}, \mathrm{b}$ \\
C1P4 & $12.4(1.4) \mathrm{A}, \mathrm{b}$ & $12.7(3.8) \mathrm{A}, \mathrm{b}$ \\
C4P1 & $13.4(3.0) \mathrm{B}, \mathrm{b}$ & $20.1(3.4) \mathrm{A}, \mathrm{a}$ \\
C4P4 & $16.2(2.9) \mathrm{A}, \mathrm{ab}$ & $13.2(1.1) \mathrm{A}, \mathrm{b}$ \\
\hline
\end{tabular}

The means followed by different capital letters in the same row and small letters in the same column are significantly different $(p<0.05)$. bond strength, with a statistically significant difference from all the other cements.

\section{Irradiance and Spectral Distribution}

Table 3 shows the irradiance values and emission peaks of the LCUs, with and without the 1.4-mm-thick ceramic bar, in shade A3. The irradiance values decreased when the light passed through the ceramic barrier, whereas the emission peaks maintained similar levels. The UltraLume LED5 showed the highest irradiance values $\left(1300 \mathrm{~mW} / \mathrm{cm}^{2}\right.$ and $715 \mathrm{~mW} / \mathrm{cm}^{2}$ when passed across ceramic material), with emission peaks at 454 and $402 \mathrm{~nm}$; the XL2500 showed the lowest values $\left(850 \mathrm{~mW} / \mathrm{cm}^{2}\right.$ and $460 \mathrm{~mW} / \mathrm{cm}^{2}$ when passed across ceramic material), with an emission peak at $490 \mathrm{~nm}$.

\section{Failure Mode Distribution}

Failure mode distribution is shown in Figure 1. The SEM analysis identified 4 different fracture types in a sample of 539 microspecimens. The most frequent fractures were Type IV (mixed). However, when the LCU factor was isolated, the fracture pattern rates showed differences: 79.3\% Type IV for LED and 92.9\% Type IV for QTH. Figures 2 and 3 show the morphology of the most frequent types

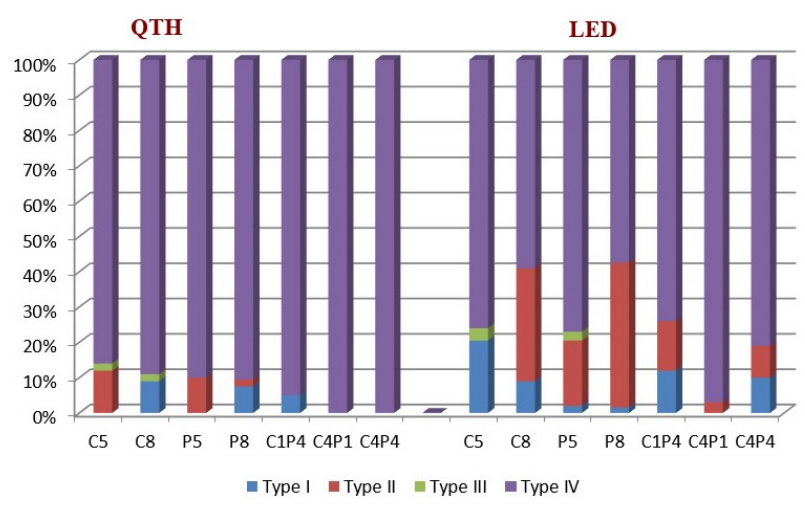

Figure 1. Graphic illustration of fracture patterns (\%) of experimental cements cured with both QTH and LED.

Table 3. Irradiance values and emission peaks of light-curing units, crossing or not the ceramic discs

\begin{tabular}{lccc}
\hline \multirow{2}{*}{$\begin{array}{l}\text { Ceramic } \\
\text { Disc }\end{array}$} & & \multicolumn{2}{c}{ Light-curing units } \\
\cline { 3 - 4 } & & $\begin{array}{c}\text { QTH } \\
\text { (XL2500) }\end{array}$ & $\begin{array}{c}\text { LED (UltraLume } \\
\text { LED5) }\end{array}$ \\
\hline \multirow{2}{*}{ No } & Irradiance & $850 \mathrm{~mW} / \mathrm{cm}^{2}$ & $1300 \mathrm{~mW} / \mathrm{cm}^{2}$ \\
& Emission peak & $487 \mathrm{~nm}$ & 454 and $402 \mathrm{~nm}$ \\
& Irradiance & $460 \mathrm{~mW} / \mathrm{cm}^{2}$ & $715 \mathrm{~mW} / \mathrm{cm}^{2}$ \\
Yes & Emission peak & $491 \mathrm{~nm}$ & 454 and $402 \mathrm{~nm}$ \\
\hline
\end{tabular}



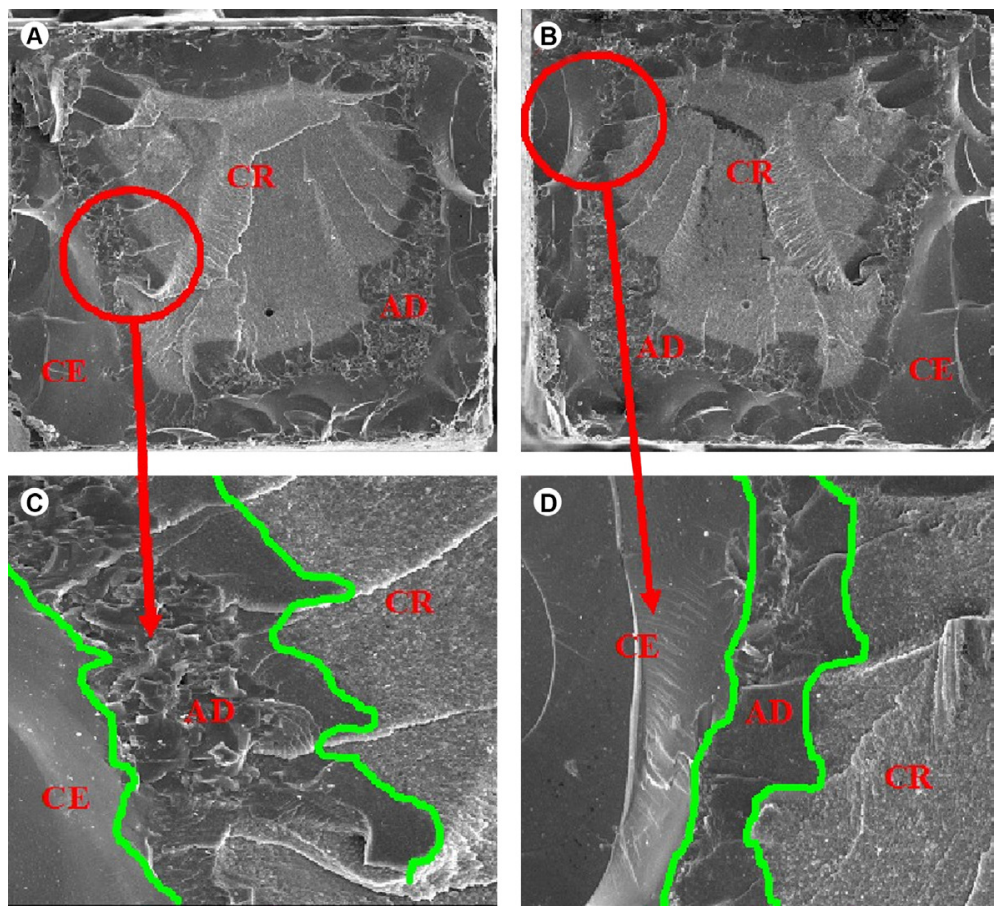

Figure 2. SEM micrographs of beams fractured within the adhesive and resin cement. Images A and B correspond to a Type IV fracture on opposite sides of the same sample, at a lower $(\times 100)$ magnification. The circles in A and B indicate the areas shown at higher $(\times 500)$ magnification in images $\mathrm{C}$ and $\mathrm{D}$, where the cohesive fractures in the ceramics (CE), involving the adhesive (AD) and resin cement (CR), can be seen in the
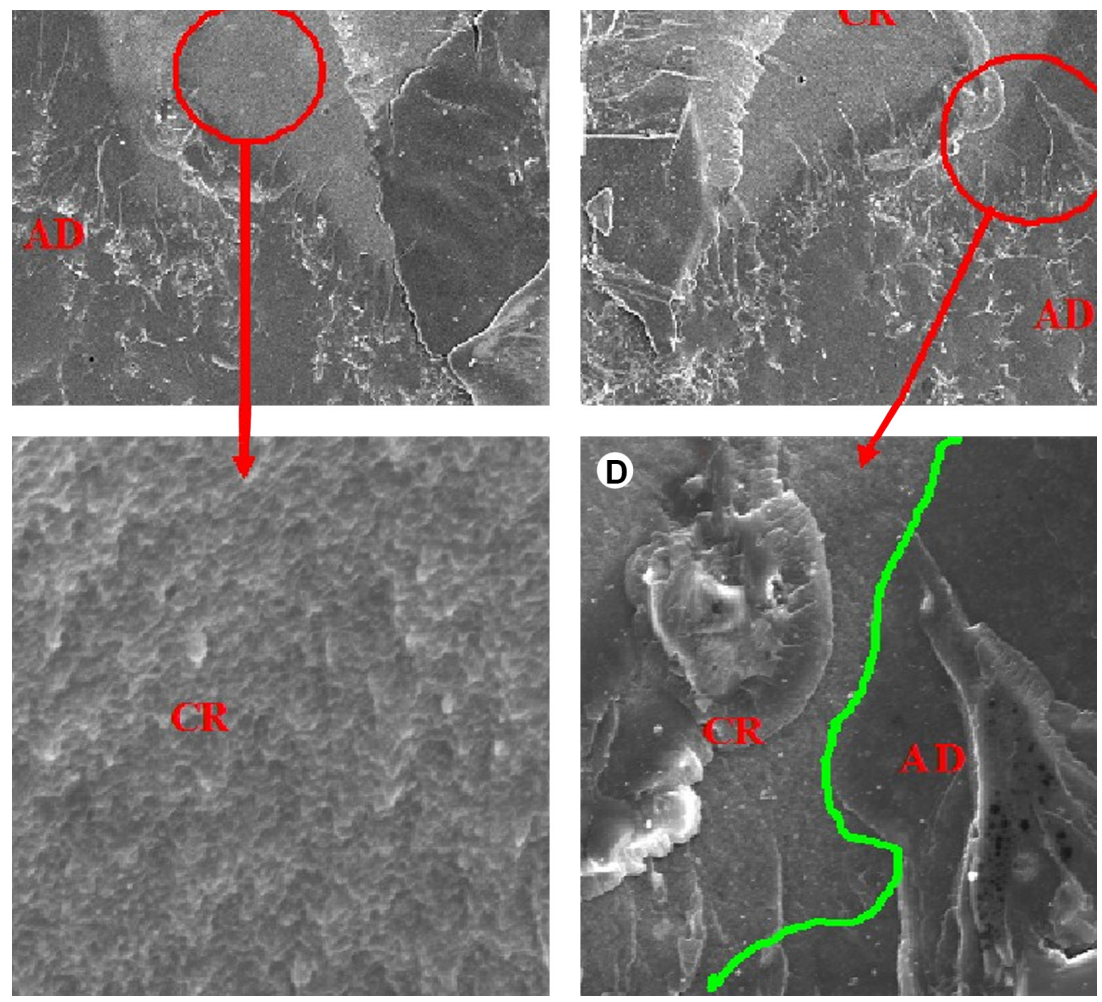

Figure 3. SEM micrographs of beams fractured at the adhesive and resin cement. Images A and B correspond to a Type IV fracture on opposite sides of the same sample at lower $(\times 100)$ magnification. The circles in A and B indicate the areas shown at higher $(\times 500)$ magnification in images $\mathrm{C}$ and D. Image C presents a cohesive failure in the resin cement (CR) that shows a superficial morphology of a dense matrix, free of porosity, involving the inorganic particles. Image D illustrates a cohesive fracture involving the adhesive (AD) and resin cement (CR) featuring surface morphology with more pronounced irregularities. 
of interfacial fractures after the microtensile test. For LED, in the C4P1 group, which showed the highest BS values, 97\% of the specimens had Type IV fractures. OTH showed some differences in fracture pattern rates; for example, in the group with the highest BS values (P5), 90\% of the specimens had Type IV fractures. Groups C5 and C4P4 presented no statistically significant differences for P5, presenting $86 \%$ and 100\% Type IV fractures, respectively.

\section{Discussion}

Considering that the traditional $\mathrm{CO} / \mathrm{amine}$ system presents some disadvantages, studies on alternative photoinitiator systems for RBCs are important. Chae and Sun (5) proposed PPD as a new visible light photosensitizer for dental composite resin with higher efficiency than CO. Park et al. (7) stated that PPD is similar to an efficient light photosensitizer and comparable to $\mathrm{CO}$, and found a synergic action between PPD and CO. Thus, this study investigated the relationship between light-curing units and photoinitiators, whether or not there is synergy between $\mathrm{C} Q$ and PPD (all containing amine) after the light crosses the ceramic discs.

The results showed that neither hypothesis should be rejected because the data varied according to the type and concentration of the studied photoinitiators as well as both sources of light. This outcome can be explained by different factors and their possible interactions. It was observed that there is no specific value for the optimal (minimal) ratio of photoinitiator to co-initiator, as there are large differences within the variants of resin-based composite components (e.g., differences in monomer types and ratios, filler types, morphology and ratio, and pigment content). Hence, the concentration of both the photoinitiator and the co-initiator, and their ratio, must be optimized for different properties (2).

The mode of failure analysis revealed a higher prevalence of Type IV fractures. The C4P1/LED and P5/QTH groups resulted in 90\% and 97\% mixed fractures, respectively, and produced the highest mean bond strength, confirming the efficiency of these combinations of light source/ photoinitiator complex. Thus, the majority of fractures occurred cohesively in both cement and adhesive types, showing a morphological appearance in relief on cement surface, characterized by a dense resin matrix with no pores around the inorganic silanized particles. These results indicated that the desired bond strength was achieved and were thus feasible for clinical use.

The C5/0TH group demonstrated a high prevalence of Type IV fractures (86\%). The morphology of this fracture mode showed good interaction between the resin cement and substrates involved in the union (ceramic and bovine dentin), likely a result of the efficiency of the light source for this material. The cohesive fractures in ceramics invariably occurred along the perimeter of the samples, possibly due to the stress concentration in this region caused by cutting the sticks.

As PPD and CQ have different wavelength absorption ranges, PPD was chosen because it would be a better UV initiator than an efficient visible light photoinitiator. Otherwise, this could be a disadvantage for the conversion of $\mathrm{C}=\mathrm{C}$, because very little energy would be concentrated in this spectral range $(390 \mathrm{~nm})$ (13). In addition, PPD is used in RBCs because it has a larger extinction coefficient than $\mathrm{CO}$. Extinction coefficient is the probability that a molecule will absorb light. Photoinitiators with a high molar extinction coefficient are more able to absorb photons, produce free radicals and presumably, contribute to higher DC values (14). Therefore, PPD was tested as an alternative photoinitiator that could become a viable alternative to CQ (15).

Both of these photoinitiators ( $C O$ and PPD) can be used without any co-initiator in light-curing composites; however, to decrease their concentrations, they are used with different co-initiators (15). The reason is simply that an excessive photoinitiator concentration affects the color of the dental composite $(4,16)$. Therefore, to enhance the photoinitiator efficiency at lower concentrations, was used $1.0 \%$ wt of the co-initiator (DMAEMA) in a fixed dosage (2:1 co-initiator-to-photoinitiator, adjusted for $0.5 \%$ of the initiator), which is consistent with other studies that found higher conversion values in that proportion, for example, when DMAEMA was used with CQ (17).

If the amine rate is lower than that of $\mathrm{CQ}$, spontaneous collision of the two substances becomes difficult and some triplet-state molecules of $\mathrm{CO}$ return to the fundamental state, thus compromising the generation of free radicals. However, if the amine concentration is higher than that of $\mathrm{CO}$, the production of radicals depends only on the reactivity of the system, because the collision of molecules is assured (18). For this reason, amine was also used with the PPD, allowing a comparison of both photoinitiators in the same conditions.

The effects of CQ and DMAEMA (19) or EDMAB (20) on $D C$ showed that several combinations of $C Q$ and amine (DMAEMA/EDMAB) would produce maximum DC. Exact agreement, in terms of the number of $\mathrm{CO}$ moles to amine, required to cause maximum $\mathrm{DC}$, would not be expected, given the differences in resin formulations and type of amine accelerators used in both studies. Yoshida and Greener (19) suggested a plateau in DC after the optimal CQ-to-amine ratio was reached, and Musange (20) showed a tendency for a decline in DC or KHN beyond a certain point above the optimal $\mathrm{CQ}$-amine concentrations.

The results also showed that there is no direct correlation between the concentration of the initiators and the 
bond strength of the cement. This fact could be due to a phenomenon known as the "blocking effect," which was associated with high CO concentrations $(14,23)$ and is characterized by the attenuation of light conduction in the material's body due to an excessive absorption of light in the superficial regions, resulting in less light transmission to the deeper layers and causing a decrease in the conversion degree (17).

Regardless of the type of initiator, it is critical for the design of the materials to incorporate more than the optimal (minimal) concentration of the photoinitiator/ coinitiator in order to avoid jeopardizing the chances of achieving maximal conversion (20), and also increasing the concentration of residual photoinitiator and amine molecules, which could leach out into the surrounding tissues and saliva.

It is also probable that the high concentrations of CQ and/or PPD were due to the decrease in effective concentration of free radicals as a result of the selfannihilation of initiator radicals, especially for QTH. Selfannihilation - the reaction between initiator radicals - is expected to increase with an increase in photoinitiator concentration in the system, due to a higher statistical $\vec{s}$ probability of initiator/radical collisions. This implies that a certain percentage of the total amount of generated free radicals are trapped at the site of their production and undergo self-annihilation instead of contributing to the polymerization process. In other words, high concentrations of both photoinitiator and coinitiator may result in the generation of a very high concentration of free radicals, with only a fraction participating in the polymerization reaction (20).

Another aspect that must be considered is the 1.4-mm thick ceramic disc, color A3 (dentin/enamel), interposed between the light source and the cementing agent, which decreased the final irradiance for both LCUs (21). Thicker or darker ceramic restorations are an obstacle to light and can reduce the quality and quantity of light incident on the resin cement, often compromising the final polymerization (22). To compensate for the attenuation of light energy resulting in the transposition of a ceramic disc, the present study included 100-s photopolymerization, which increases the absorption of photons by the initiators for both light sources. This suggests future studies of different curing times.

The absorption peak of PPD is closer to the ultraviolet spectrum that does not correspond to the higher energy in the QTH light source, but this initiator has a high molar extinction coefficient that indicates a high absorption efficiency of photons (23). When photoactivated by QTH, the combination of equal parts of PPD and CQ led to high values of bond strength, probably for two reasons: 1) a higher number of molecules available to absorb photons and produce free radicals favoring the conversion degree and, consequently, the mechanical properties (8); and 2) the conversion rate may have been slower due to the different molar extinction coefficients and absorbance spectra of the initiators, allowing for the dissipation of the polymerization shrinkage stresses (24). However, the present study showed similar results for both light sources. This is likely due to both UltraLume LED5 and the OTH-XL2500 delivering a wide range of wavelengths; therefore, they were able to adequately initiate both $\mathrm{CQ}$ and PPD.

PPD is a highly viable alternative for use in the formulation of photocured resin cements because it allows for the reduction or elimination of $\mathrm{CQ}$, which can cause yellowness without impairing bond strength. Furthermore, both LED and QTH are effective in curing resin cements containing PPD or $\mathrm{CQ}$; in different concentrations, they also ensure desired bond strength, even within an $\mathrm{A} 3$ color 1.4-mm-thick ceramic disc.

\section{Resumo}

Este estudo avaliou a resistência de união (BS) de cimentos resinosos experimentais formulados com diferentes fotoiniciadores, quando ativados através de cerâmica, por dois tipos de fontes luminosas (LCUs). Foram preparadas sete formulações com diferentes concentrações em peso (wt) de canforquinona (CO) e/ou fenilpropanodiona (PPD): C5: 0,5\%CQ; C8: 0,8\%CQ; P5: 0,5\%PPD; P8: 0,8\%PPD; C1P4: 0,1\%CQ e 0.4\%PPD; C4P1: 0,4\%CQ e 0,1\%PPD; C4P4: 0,4\%CQ e 0,4\%PPD. Duas LCUs foram usadas: uma com luz halógena (OTH $-850 \mathrm{~mW} / \mathrm{cm}^{2}$ ) e uma com diodo emissor de luz (LED - $1300 \mathrm{~mW} / \mathrm{cm}^{2}$ ). A BS foi avaliada por teste de microtração. Os dados foram submetidos a ANOVA a dois fatores e Teste de Tukey $(\alpha=0,05)$. Isolando o tipo de fotoiniciador, não houve diferenças significativas na BS. Três cimentos mostraram diferenças significativas: a BS foi maior para P5 e C5 com QTH; e para C4P1 com LED. Para a QTH, P5 exibiu a maior e C1P4 a menor BS. Para LED, C4P1 exibiu a maior BS de todos os outros cimentos testados. Conclusão: PPD é altamente viável em formulações de cimentos resinosos fotopolimerizáveis, reduzindo ou eliminando a CO que é amarelada, sem comprometer a resistência de união. Além disso, tanto LED quanto OTH são efetivas para polimerizar os cimentos contendo PPD ou CO.

\section{References}

1. Lührs AK, De Munck J, Geurtsen W, Van Meerbeek B. Composite cements benefit from light-curing. Dent Mater 2014;30:292-301.

2. Davidson C.L. Luting cement, the stronghold or the weak link in ceramic restorations. Adv Engin Mater 2001;3:763-767.

3. Aguiar T, Francescantonio M, Arrais C, Ambrosano G, Davanzo C, Giannini M. Influence of curing mode and time on degree of conversion of one conventional and two self-adhesive resin cements. Oper Dent 2010;35:295-299.

4. Akgungor G, Akkayan B, Gaucher H. Influence of ceramic thickness and polymerization mode of a resin luting agent on early bond strength and durability with a lithium disilicate-based ceramic system. J Prosth Dent 2005;94:234-241.

5. Chae KH, Sun GJ. Phenylpropanedione: A new visible light photosensitizer for dental composite resin with higher efficiency than camphorquinone. Bull Kor Chem Soc 1998;19:152-154.

6. Schneider LFJ, Pfeifer CSC, Consani S, PrahI SA, Ferracane JL. Influence of photoinitiator type on the rate of polymerization, degree of conversion, hardness and yellowing of dental resin composites. Dent 
Mater 2008:24:1169-1177.

7. Park YJ, Chae KH, Rawls HR. Development of a new photoinitiation system for dental light-cured composites resin. Dent Mater 1999;15:120-127.

8. Schneider LFJ, Cavalcante LM, Consani S, Ferracane JL. Effect of co-initiator ratio on the polymer properties of experimental resin composites formulated with camphorquinone and phenylpropanedione. Dent Mater 2009;25:369-375.

9. Soares $E F$, Costa $A R$, Correr $A B$, Vedovello $S A$, Vedovello Filho $M$, Ogliari $F A$, et al.. Effect of composite containing an iodonium salt on the bond strength of brackets to bovine enamel. Braz Dent J 2014;25:237-240.

10. Oliveira DC, Silva CB, Muniz BV, Volpato MC, Costa $A R$, Sinhoreti MA. Effect of 4-(N,N-dimethylamino)phenethyl alcohol on degree of conversion and cytotoxicity of photo-polymerized CQ-based resin composites. Braz Dent J 2014;25:538-542.

11. Arikawa $H$, Takahashi $H$, Kanie T, Ban S. Effect of various visible light photoinitiators on the polymerization and color of light-activated resins. Dent Mat J 2009;28:454-460.

12. Gajewski VE, Pfeifer CS, Fróes-Salgado NR, Boaro LC, Braga RR. Monomers used in resin composites: degree of conversion, mechanical properties and water sorption/solubility. Braz Dent J 2012;23:508-514.

13. Brandt WC, Schneider LFJ, Frollini E, Correr-Sobrinho L, Sinhoreti MAC. Effect of different photo-initiators and light curing units on degree of conversion of composites. Braz Oral Res 2010;24:263-270.

14. Shin DH, Rawls HR. Degree of conversion and color stability of the light curing resin with new photoinitiator systems. Dent Mater 2009;25:1030-1038.

15. Brandt WC, Silva CG, Frollini E, Souza-Junior EJC, Sinhoreti MAC. Dynamic mechanical thermal analysis of composite resins with $\mathrm{CO}$ and PPD as photo-initiators photoactivated by QTH and LED units. J Mech Behav Biomed Mater 2013;24:21-29.

16. Brandt WC, Tomaselli LO, Correr-Sobrinho L, Sinhoreti MAC.
Can phenyl-propanedione influence Knoop hardness, rate of polymerization and bond strength of resin composite restorations? J Dent 2011;39:438-447.

17. Teshima W, Nomura $Y$, Tanaka N, Urabe H, Okazaki M, Nahara Y. ESR study of camphorquinone/amine photoinitiator systems using blue light-emitting diodes. Biomat 2003;24:2097-2103.

18. Cook WD. Photopolymerization kinetics of dimethacrylates using the camphorquinone/amine initiator system. Polymer 1992;33:600-609.

19. Yoshida K, Greener EH. Effects of two amine reducing agents on the degree of conversion and physical properties of an unfilled light-cured resin. Dent Mater 1993;9,246-251.

20. Musaje L, Ferracane JL, Sakaguchi RL. Determination of the optimal photoinitiator concentration in dental composites based on essential material properties. Dent Mater 2009;25,994-1000.

21. O'Keefe $\mathrm{KL}$, Pease $\mathrm{PL}$, Herrin HK. Variables affecting the spectral transmittance of light through porcelain veneers. J Prosth Dent 1991;66,434-438.

22. Runnacles P, Correr GM, Baratto Filho F, Gonzaga CC1, Furuse AY. Degree of conversion of a resin cement light-cured through ceramic veneers of different thicknesses and types. Braz Dent J 2014;25:38-42.

23. Neumann MG, Miranda Jr WG, Schmitt CC, Rueggeberg FA, Correa IC. Molar extinction coefficients and photon absorption efficiency of dental photoinitiators and light curing units. J Dent 2005;33:525-532.

24. Schneider LFJ, Consani S, Sakaguchi RL, Ferracane JL. Alternative photoinitiator system reduces the rate of stress development without compromising the final properties of the dental composite. Dent Mater 2009;25:566-572.

Received July 3, 2015 Accepted December 16, 2015 